\title{
SPECIAL ISSUE EDITORIAL: \\ Next Generation ICTs - How distant is ubiquitous computing?
}

PUBLISHED: March-August 2021

DOI: $10.36680 /$ j.itcon.2021.033

Dr. Kirti Ruikar, Senior Lecturer, School of Architecture, Building and Civil Engineering, Loughborough University, UK.

Dr. Ketan Kotecha, Director, SIT; Director, Symbiosis Centre for Applied Artificial Intelligence (SCAAI); Dean of Engineering, Symbiosis International (Deemed University), India.

Dr. Sayali Sandbhor, Assistant Professor, Civil Engineering Department, Symbiosis Institute of Technology (SIT), India.

Dr. Albert Thomas, Assistant Professor,

Department of Civil Engineering, Indian Institute of Technology Bombay, Mumbai, India.

Traditional design development processes have come a long way from the use of drawing boards. The accelerated use of ICT-based digital systems means that the industry has steadily moved towards a digitized future. A future where increasingly unstructured information is created, shared, manipulated, stored, and archived in various digital media support the four pillars of visualization, integration, communication, and intelligence on which typical construction projects currently stand. The ICT field's growth, combined with the unprecedented advances in communication and network media usage, has resulted in hyper-interconnectivity globally. This hyperconnectivity through developments such as the Internet of Things (IoT) creates global opportunities for collaboration, which was not previously possible. It links 'human' and 'social' networks with 'technical' systems. With the vast volumes of digitally connected systems and the systems' data, new opportunities for learning have surfaced in the construction domain. The special issue targeted the state-of-the-art developments of next generation ICTs in the global arena. As with any new developments, new opportunities emerge and new challenges surface. The cautious late majority and the laggards, adopt a skeptical approach, that which is reserved and strewn in doubt. The innovators and the early majority on the other hand pave the way to technology adoption and help drive change in the industry. This special issue recognises that the emergence of next-generation ICTs, combined with developments in ubiquitous computing, presentopportunities that challenge the current status quo of the construction sector. This special issue recognizes that for an industry to remain truly competitive, due consideration need to be given to the ongoing and emerging technological developments, and a deep understanding of which would lead to novel responsive approaches for their significant uptake.

The collection of papers in this special issue gives a comprehensive overview of research and developments in the field of next-generation ICTs. It bridges the gap between the two domains of construction and computer science. Of the ten papers in this collection, two (by Akamu et al, and Karmarkar and Delhi) were invited papers and include a world view on thewider applicability of next-generation ICTs in the construction domain, the opportunities they present and the challenges that emerge. The remaining papers, amongst other aspects, cover theinnovative application of next-gen ICTs in specific industry sectors(e.g., in the water industry by Alani et al, 2021)or in meeting specific project goals such as to manage energy consumption (Watfa et al), improve information retrieval (Wang et al), integrate AR and BIM for specific building submission processes (Schranz et al), identify challenges to collaborative working within globally dispersed virtual project teams (Anderson and Ramalingam), and ontology for robot navigation and data fusion (Karimi et al). 
Akamu et al present potential scenarios of next generation cyber physicalsystems (CPS) and digital twins (DT) for improving workforce productivity, health and safety, lifecycle management of buildingsystems, and workforce competency. They highlight the various benefits of next generation CPS and DTs and point to the challenges that need to beaddressed to advance the implementation of their applications in construction. For instance, they point to the need to establish information models for DT applications so that the semanticsof any relationships, rules and constraints from data that are critical for understanding the behavior of physicalsystems and artifacts are suitably represented. This they postulate, is an essential ingredient for the implementation of the next generation CPS and DTapplications. Additionally, this point to the need for guidelinesto define and manage the different versions of DTs. This could be achieved through "digitally tracked twins", a vision proposed by Ruikar in 2019. The challenges are not simply limited to the examples included in this editorial but are discussed in further depth in the paper. In conclusion, Akamu et al stress that two-way CPS integration between the DTs and physicalsystems would offer huge potential for improving predictability and control, with key enabling technologies such as those for virtual design modeling, sensing, data analysis, storage and communication, human-computer interaction, and robotics.

Similarly, Karmarkar and Delhi present a "world view" of construction 4.0 and conceptualise the continuous and complex network ofinteractions spanning across four layersthat include the 1) physical, 2) digital tools', 3) data, and 4) central data management layers. They postulate that the roles and functions of people involved are significantly altered withthe advent of the construction 4.0 paradigm. The paper discusses how in response to the construction 4.0 paradigm, new organizational roles have emerged, new models of interactions between people andtechnology have emerged and the demand fordefined processes that support this emergent need has been compounded. Significant progress has been made in the technologies associated with Construction 4.0. However, specific vitalchallenges remain that need to be addressed to facilitate the mainstreaming of digitalization. Globally, suchchallenges include but not limited to the alignment of incentive mechanisms of various stakeholders, skilling, andtraining of personnel to accept the technologies, project lifecycle integration in a fragmented industry, specificprocess-related changes to facilitate digital technologies, and policy frameworks to enable digital data security andintegrity for the projects. Therefore, such challenges span the technology, social, economic, and policy spheres. Synergetic approaches to encourage industry-wide adoption combined with conducive contractual frameworksand digital-ready processes with skilled teams are therefore crucial in achieving the benefits exhibited by the technologicaladvancements in this space.

Meanwhile, Deng et al, through a review, identified developmentsin emerging technologies that have enabled the advancement of BIM to Digital Twins in built environment. They developed a five-level ladder categorization system based on the building life cycle to reflect the current state-of-the-art in Digital Twin applications. They observed that although several recent studies start with the intent of applying BIM for higher-levelapplications (Levels 4 and 5), they generally limit themselves to staying within the BIMLevel 2 and Level 3 categories. This points to the need for Digital Twin to contain, not only real-time monitoring and prediction capabilities, but also capabilities that enable automated feedback control for adjustment of building parameters as and when necessary.

Similarly, Wang et al discuss the problems associated with BIM retrieval systems and propose a multi-scale building information retrieval scheme from BIM models. A BIM is seen as a large knowledgebase, that includes data and information about various components that make up the model, and this presents several learning opportunities. The multi-scale building information retrieval scheme proposed would therefore enable the data and information contained in a model to be better organized, managed, and understood.

Likewise, Watfa et al explore building information and energy modelling for improved design efficiency in a residential building in UAE. Energy consumption was modelled by studying various design considerations such as building orientation, window types, sizes, and distribution and their overall impact on energy consumption. The research demonstrated a reduction in energy use by $8 \%$ by modifying the building's orientation, and a further reduction was achieved with alterations to the window wall ratio (2\% reduction) and through the using double glazing ( $2 \%$ reduction).

Meanwhile, Schranz et al explore the potential of augmented reality in a BIM based building submission process. With the help of use-cases they demonstrate how an AR-based plan checking process, along with the model-based communication capability could improve the presentation of the technical content and enhance the general public's understanding of the planned project within the context of the real environment. 
Parisi et al's research examines the application of ICTs to Intelligent Building (IB) lifecycle processes. The review analysis is performed by using aframework that consists of a hierarchical two-layerstructure, of which the lowest layer, which contains one construction-specific sub-layer and oneICT generic sub-layer. The components of the ICT generic sub-layer are identified by a procedure supported bynatural language processing technique. The defined methodology could be applied for a review analysis in different research contexts where many aspects and documents need to be considered. Several potential benefits of the proposed methodology are discussed, including among other aspects, theautomatic capability to explore paper contents without the need for any aprioriassumptions.

Meanwhile, Anderson and Ramalingam conducted an experimental study of global virtual teams from USA and India to explore the role of project teams in temporary organisations and the role of BEP as a pre-process intervention strategy. Findings of this study showed thatcoordinating project tasks virtually was found to be challenging. The paper makes some useful observations and recommendations for geographically and technically diverse teams, so their collaboration objectives are met.

Karimi et al similarly developed a semantic web ontology-based approach for integrating robot navigation and data collection to translate the BIM-GIS information to the robot's navigation system. For developing the proposed Building Information Robotic System (BIRS), the researchers developed robot operating system integrated with site database. Findings of the application of the system to four case studies helped in validating the model. The study provides a reliable tool for continuous progress monitoring and automatic data collection of construction projects.

Furthermore, Alani et al targets to resolve the interoperability issues within the infrastructure project players and presents investigations of the application of Semantic Web Technologies (SWT) for improving product data exchange during product procurement during facility management phase for the United Kingdom's water industry. The authors recommend his paper a common model or a product library for phase-specific product data exchange as a concluding remark.

This special issue has brought together people from the UK and India to join hands as the guest editors. It has given opportunity to the researchers across the globe to put their perspectives about the Next gen ICTs. The process of handling manuscripts was smooth with Mrs. Vaishnavi Dabir's flawless editorial assistance throughout. The core team of the special issue wishes to thank the entire team of ITCon, especially Prof. Robert Amor, all the contributors of the special issue, authors of the invited articles and Mrs. Vaishnavi Dabir (Editorial Assistant)!

\section{REFERENCES}

Akanmu A A, Anumba C J, Ogunseiju O O (2021). Towards next generation cyber-physical systems and digital twins for construction, ITcon Vol. 26, Special issue Next Generation ICT - How distant is ubiquitous computing?, pg. 505-525, doi:10.36680/j.itcon.2021.027

Alani Y, Dawood N, Patacas J, Rodriguez S, Dawood H (2021). A semantic common model for product data in the water industry, ITcon Vol. 26, Special issue Next Generation ICT - How distant is ubiquitous computing?, pg. 566-590, doi:10.36680/j.itcon.2021.030

Anderson A, Ramalingam S (2021). A socio-technical intervention in BIM projects - an experimental study in global virtual teams, ITcon Vol. 26, Special issue Next Generation ICT - How distant is ubiquitous computing?, pg. 489-504, doi:10.36680/j.itcon.2021.026

Deng M, Menassa C C, Kamat V R (2021). From BIM to digital twins: a systematic review of the evolution of intelligent building representations in the AEC-FM industry, ITcon Vol. 26, Special issue Next Generation ICT - How distant is ubiquitous computing?,pg. 58-83, doi:10.36680/j.itcon.2021.005

Karimi S, Iordanova I, St-Onge D (2021). Ontology-based approach to data exchanges for robot navigation on construction sites, ITcon Vol. 26, Special issue Next Generation ICT - How distant is ubiquitous computing?, pg. 546-565, doi:10.36680/j.itcon.2021.029 
Karmakar A, Delhi V S K (2021). Construction 4.0: what we know and where we are headed?, ITcon Vol. 26, Special issue Next Generation ICT - How distant is ubiquitous computing?, pg. 526-545, doi:10.36680/j.itcon.2021.028

Parisi F, Fanti M P, Mangini A M (2021). Information and Communication Technologies applied to intelligent buildings: a review, ITcon Vol. 26, Special issue Next Generation ICT - How distant is ubiquitous computing?, pg. 458-488, doi:10.36680/j.itcon.2021.025

Schranz C, Urban H, Gerger A (2021). Potentials of Augmented Reality in a BIM based building submission process, ITcon Vol. 26, Special issue Next Generation ICT - How distant is ubiquitous computing?, pg. 441-457, doi:10.36680/j.itcon.2021.024

Wang J, Gao X, Zhou X, Xie Q (2021). Multi-scale Information Retrieval for BIM using Hierarchical Structure Modelling and Natural Language Processing, ITcon Vol. 26, Special issue Next Generation ICT - How distant is ubiquitous computing?,pg. 409-426, doi:10.36680/j.itcon.2021.022

Watfa M K, Hawash A E, Jaafar K (2021). Using Building Information \& Energy Modelling for Energy Efficient Designs, ITcon Vol. 26, Special issue Next Generation ICT - How distant is ubiquitous computing?, pg. 427-440, doi:10.36680/j.itcon.2021.023 